\title{
Resistência à compressão de concretos com agregados reciclados provenientes de construção e demolição: revisão de literatura
}

\author{
Poliana Souza Maia ${ }^{1}$ \\ Malheny Vitoria Silva Carvalho ${ }^{2}$ \\ Ladir Antonio Silva Junior ${ }^{3}$ \\ Pedro Valle Salles ${ }^{4}$
}

\begin{abstract}
RESUMO
Com intuito de contribuir com técnicas construtivas mais sustentáveis, nos últimos anos surgiram várias pesquisas experimentais com a substituição do agregado natural em concretos estruturais, por agregados de resíduo de construção e demolição (RCD). Diante disso, esta pesquisa realizou um levantamento bibliográfico de algumas pesquisas nacionais realizadas nesta área, com o intuito de verificar as tendências e divergências de comportamento entre os traços fabricados com RCD e elucidar boas práticas para as futuras pesquisas. Por meio da análise dos resultados, constata-se que o abatimento e a resistência à compressão do concreto são as propriedades mais afetadas negativamente pela substituição do agregado natural pelo agregado de RCD e que para obter um concreto com bom desempenho é necessário adotar medidas que visam melhorar as propriedades perdidas com a incorporação de RCD no concreto. Conclui-se que por meio de boas técnicas é possível produzir concretos com agregados de RCD com valores de resistência à compressão similares ao concreto convencional.
\end{abstract}

Palavras-chave: Agregado Reciclado. RCD. Substituição de Agregado.

\footnotetext{
${ }^{1}$ Graduada em Engenharia Civil pela Universidade do Estado de Minas Gerais - UEMG, Unidade João Monlevade, MG, Brasil. E-mail: polianamaaia@ hotmail.com.

${ }^{2}$ Graduada em Engenharia Civil pela Universidade do Estado de Minas Gerais - UEMG, Unidade João Monlevade, MG, Brasil. E-mail: malheny.0615886@ discente.uemg.br.

${ }^{3}$ Graduado e Mestre em Engenharia Civil pela Universidade Federal de Viçosa - UFV. É engenheiro na Projettari - Engenharia \& Arquitetura e também é professor e pesquisador da Universidade do Estado de Minas Gerais - UEMG, Unidade João Monlevade, MG, Brasil. E-mail: ladir.jr@gmail.com.

${ }^{4}$ Graduado em Engenharia Civil pela Universidade Federal de Minas Gerais - UFMG. Mestre e Doutorando em Engenharia Civil pelo Centro Federal de Educação Tecnológica de Minas Gerais - CEFET. Atua na Construção Civil e também é professor e pesquisador da Universidade do Estado de Minas Gerais - UEMG, Unidade João Monlevade, MG, Brasil. E-mail: pedro.salles@uemg.br.
} 


\title{
Compressive strength of concrete with recycled aggregates from construction and demolition: literature review
}

\begin{abstract}
In order to contribute to sustainable practices, several experimental studies considering the replacement of natural aggregate in structural concretes by construction and demolition waste $(C D W)$ were performed. This paper presents a literature review of some Brazilian researches carried out in this science area, with the aim of verifying the trends and divergences of behavior of concrete mixes produced with $C D W$ and elucidating good practices for future research. The results obtained by the authors of the analyzed researches states that the slump test and the uniaxial compressive strength were the properties most negatively affected by the replacement of the natural aggregate by the $C D W$. Then, to obtain a concrete with good performance, it is necessary to adopt procedures to improve the loss of properties with the incorporation of CDW in the concrete. Trough good practices, the production of a concrete with construction and demolition waste with similar property values compared with the conventional concreate is possible.
\end{abstract}

Keywords: Recycled Aggregate. CDW. Aggregate Replacement.

Artigo recebido em: 10/12/2020

Aceito em: 29/04/2021 


\section{INTRODUÇÃO}

As constantes inovações e descobertas na área da construção civil fizeram com que a utilização do concreto se propagasse largamente e possibilitasse o emprego do material em grande escala e com diversas aplicações. De acordo com Pedroso (2009), aproximadamente 11 bilhões de toneladas de concreto são consumidas no mundo, liderando o segundo maior item de consumo por habitante. De acordo com a Federacion Interamericana Del Cemento FICEM (2018), no ano de 2017 na América latina, foram consumidas 179.469 toneladas de cimento, sendo que no Brasil o consumo per capito de cimento neste mesmo ano foi de $261 \mathrm{~kg}$. Entretanto, esse grande uso traz consigo alguns problemas ambientais ligados à escassez de recursos naturais e à produção de resíduos uma vez que o consumo de cimento de forma indireta, indica o consumo de concreto, que por sua vez, acarreta em grande consumo de agregados.

Grande parte das matérias-primas empregadas na construção civil é oriunda de fontes não renováveis, o que torna o setor um grande consumidor de recursos naturais como também um dos principais geradores de resíduos (ORTEGA, 2014). Segundo Lauriano (2013), o setor da construção civil é responsável pelo consumo de 75\% dos recursos naturais, e conforme a Associação Nacional das Entidades de Produtores de Agregados para Construção - ANEPAC (2015), o consumo de agregados no Brasil em 2014 atingiu 714 milhões de toneladas, o que corresponde a 3,7 toneladas/habitante/ano.

No mesmo ano, segundo o relatório publicado pela Associação Brasileira de Empresas de Limpeza Pública e Resíduos Especiais - ABRELPE (2015), a quantidade de resíduo de construção e demolição (RCD) coletada por dia nos municípios brasileiros foi de 122.262 toneladas, que significa 0,603 quilogramas/habitante/dia. A coleta de RCD em 2015 sofreu aumento de 1,19\% em relação ao ano anterior e os relatórios dos anos seguintes mostram que houve leve redução no total de RCD descartados sendo que em 2018 foram 122012 toneladas/dia, isso representa queda de $0,2 \%$ em relação a 2014 (ABRELPE, 2015, 2016, 2018/2019). Entretanto, os números reais de resíduos de construção e demolição gerados no Brasil são ainda maiores, pois os dados dos relatórios da ABRELPE se referem essencialmente aos resíduos abandonados em locais públicos, já que as construtoras devem descartar o seu RCD em local apropriado.

Diante deste cenário, tanto a demanda por matéria-prima, quanto a geração de resíduos são potenciais causas de diversos problemas ambientais. Dentre os quais pode-se citar os 
mais evidentes como a degradação do solo e a poluição do ar e de cursos d'agua, é necessário que as empresas do ramo da construção adotem práticas sustentáveis que visem à redução do consumo de recursos naturais bem como evitar o descarte de resíduos que podem voltar para a cadeia produtiva.

Sendo assim, umas das possíveis soluções para isso é reutilizar os resíduos de construção e demolição como agregado no concreto. Entretanto, a variedade da composição dos agregados reciclados de RCD é um obstáculo para a sua aplicação, pois contém diferentes percentuais de concreto, argamassa, materiais cerâmicos e outros elementos constituintes. Além disso, apresentam diferentes granulometrias, massas específicas e porcentagens variáveis de absorção de água (ANGULO, 2000).

Diante disso, esta pesquisa tem por objetivo realizar uma revisão bibliográfica sobre o desempenho do concreto com a substituição dos agregados naturais pelo agregado de RCD, tanto para o agregado graúdo, como para o agregado miúdo. Esta pesquisa possui o intuito, por meio da exposição dos resultados experimentais da literatura, de elucidar boas práticas para os futuros trabalhos que possuam o objetivo de estudar esta temática de pesquisa e contribuir com o avanço tecnológico da área.

Para isso, selecionou-se os principais estudos experimentais desenvolvidos no país, com o intuito de entender os diferentes tipos de comportamento do concreto que possui a incorporação de agregados de RCD. O critério de seleção desses trabalhos foi baseado na abrangência e diversidade de resultados, que mostram a grande variabilidade e as possíveis influências que a substituição ou adição de agregado de RCD podem provocar no concreto. Assim sendo, na definição dos estudos experimentais apresentados nesse artigo, não foi dada a maior importância para o ano dos estudos e sim para o tipo de ensaio e os resultados apresentados com o propósito de expor ao leitor desse artigo as variabilidades, as vantagens e desvantagens que a utilização do RCD pode causar na resistência do concreto.

Com intuito de elucidar os leitores sobre o assunto abordado, neste trabalho foi elaborado um breve referencial teórico, com a exposição de conceitos para a fundamentação do tema abordado. Posteriormente são apresentados os estudos experimentais selecionados, destacando seus principais resultados e conclusões. A partir dos resultados obtidos, é realizada uma discussão sobre o assunto, mostrando suas tendências e divergências, indicando as possíveis linhas de pesquisas a serem elaboradas no futuro. 


\section{REFERENCIAL TEÓRICO}

\subsection{Composição do concreto}

O concreto é um material formado por mistura de cimento, agregado graúdo, agregado miúdo e água. Além disso, sabe-se que o concreto pode incorporar diversos materiais em sua composição. Segundo Neville e Brooks (2013), o concreto pode ser fabricado com diferentes tipos de cimentos e, além disso, pode conter aditivos, agregados de concreto reciclado, adições minerais, polímeros, cinzas volantes, fibras, sílica ativa e escória de alto-forno. E ainda, de acordo com os mesmos autores, para produzir um bom concreto deve-se atender a dois critérios: boa consistência no estado fresco e boa resistência no estado endurecido.

O agregado natural, segundo Bauer (2008, p.63), é definido como um "material particulado, incoesivo, de atividade química praticamente nula, constituído de misturas de partículas cobrindo extensa gama de tamanhos". Além disso, as propriedades dos agregados podem afetar a durabilidade, a resistência e o desempenho estrutural do concreto (NEVILLE, 2016).

O agregado pode ser classificado pela sua granulometria como agregado graúdo e miúdo, sendo mais conhecido respectivamente como brita e areia. A NBR 7211 (ABNT, 2005) faz esta classificação de acordo com o ensaio de granulometria, sendo que o agregado miúdo é aquele cujos grãos passam pela peneira com abertura de malha de $4,75 \mathrm{~mm}$ e ficam retidos na peneira com abertura de malha de $150 \mu \mathrm{m}$, e o agregado graúdo é aquele cujos grãos passam pela peneira com abertura de malha de $75 \mathrm{~mm}$ e ficam retidos na peneira com abertura de malha de $4,75 \mathrm{~mm}$.

\subsection{Resíduos da Construção e Demolição: definição e agregado proveniente do RCD}

A Associação Brasileira para Reciclagem de Resíduos da Construção Civil e Demolição - ABRECON (2019) diz que todo resíduo gerado no processo construtivo, de escavação, reforma ou demolição é denominado, tecnicamente, como Resíduo da Construção e Demolição (RCD) ou Resíduo da Construção Civil (RCC). E ainda, segundo a Resolução do CONAMA nº 307 (BRASIL, 2002), esses resíduos são normalmente chamados de entulhos de obra, metralha ou caliça. 
É importante ressaltar que a produção desses resíduos traz consigo diversos impactos ao meio ambiente. Segundo Neto et al. (2004), a geração de RCD pode causar impactos físicos, econômicos, sociais, ambientais e sanitários. Os impactos ambientais e sanitários se referem à poluição visual, ao assoreamento da várzea de rios e a geração de poeira e ruído durante as etapas de coleta, transporte e tratamento. Os impactos físicos são os danos causados no local do acondicionamento dos resíduos, e interferências no trânsito durante a coleta e o transporte. Os impactos econômicos se referem à desvalorização das áreas ocupadas pelos resíduos e aos gastos para recuperar essas áreas. E os impactos sociais dizem respeito a queda da qualidade de vida da população que vive próxima aos locais de disposição dos entulhos.

O agregado reciclado é um material granular oriundo do beneficiamento de resíduos da construção civil, resíduos estes que apresentam atributos técnicos que permitem a sua utilização em obras de infraestrutura, de edificação, em aterros ou outras obras de engenharia (BRASIL, 2002).

A Resolução do CONAMA n ${ }^{\circ}$ 307, classifica os resíduos da construção civil em quatro grupos:

I - Classe A - são os resíduos reutilizáveis ou recicláveis como agregados, tais como:

a) de construção, demolição, reformas e reparos de pavimentação e de outras obras de infra-estrutura, inclusive solos provenientes de terraplanagem;

b) de construção, demolição, reformas e reparos de edificações: componentes cerâmicos (tijolos, blocos, telhas, placas de revestimento etc.), argamassa e concreto;

c) de processo de fabricação e/ou demolição de peças pré-moldadas em concreto (blocos, tubos, meio-fios etc.) produzidas nos canteiros de obras;

II - Classe B - são os resíduos recicláveis para outras destinações, tais como: plásticos, papel/papelão, metais, vidros, madeiras e outros;

III - Classe C - são os resíduos para os quais não foram desenvolvidas tecnologias ou aplicações economicamente viáveis que permitam a sua reciclagem/recuperação, tais como os produtos oriundos do gesso;

IV - Classe D: são resíduos perigosos oriundos do processo de construção, tais como tintas, solventes, óleos e outros ou aqueles contaminados ou prejudiciais à saúde oriundos de demolições, reformas e reparos de clínicas radiológicas, instalações industriais e outros, bem como telhas e demais objetos e materiais que contenham amianto ou outros produtos nocivos à saúde. (BRASIL, 2002, p.2 ).

Os resíduos de Classe A podem ser divididos em dois grupos: agregado de resíduo de concreto e agregado de resíduo misto. A NBR 15116 (ABNT, 2004) classifica os resíduos de Classe A de acordo com os seguintes requisitos:

- Agregado de Resíduo de Concreto (ARC): constituído na sua porção graúda de no mínimo 90\% em massa de componentes a base de cimento Portland e rochas; 
- Agregado de Resíduo Misto (ARM): constituído na sua porção graúda com menos de $90 \%$ em massa de componentes a base de cimento Portland e rochas.

A variedade da composição dos agregados reciclados de RCD é um obstáculo para a sua aplicação, pois contém diferentes percentuais de concreto, argamassa, materiais cerâmicos e outros elementos constituintes. Além disso, podem ter diferentes granulometrias, massa específica e porcentagens variáveis de absorção de água. Por tais motivos, antes de empregar agregado reciclado no concreto é necessário estudar as propriedades e a composição do RCD para que seja possível analisar o desempenho do concreto fabricado a partir destes (ANGULO, 2000).

\section{RESULTADOS}

Nos resultados deste artigo são apresentados seis estudos experimentais encontrados na literatura. A escolha desses estudos foi baseada principalmente em dois parâmetros que são: os resultados de resistência a compressão e trabalhabilidade. Além desses, a variabilidade dos traços utilizados, os tipos de agregados de RCD e processos metodológicos utilizados, também foram fatores importantes para a escolha dos estudos analisados. Cada estudo selecionado mostra uma tendência de comportamento, a partir dos traços e materiais selecionados. Em seguida, verificou-se as tendências e as divergências de comportamento entre os traços estudados, para assim entender o que deve ser analisado no momento de se realizar um estudo experimental com esse tipo de material.

\subsection{Bazuco (1999)}

Bazuco (1999) realizou um estudo da utilização de agregado graúdo reciclado de concreto para a produção de novos concretos. Com intuito de avaliar o desempenho de diferentes traços de concreto utilizando agregado graúdo reciclado em substituição ao agregado graúdo convencional, foram adotados os seguintes teores de substituição: 0\%, $25 \%, 50 \%, 75 \%$ e $100 \%$. Observou-se que à medida que os agregados naturais foram sendo substituídos, a taxas crescentes, a porcentagem ideal de argamassa das misturas teve que ser aumentada para se manter a mesma trabalhabilidade e coesão.

Para a produção dos concretos, o autor confeccionou misturas com os agregados reciclados no estado seco e saturado. Para a confecção dos concretos com agregados 
saturados, foi realizado a imersão em água dos mesmos por um período de 24 horas, e antes da sua utilização os agregados foram expostos ao ar por aproximadamente 15 min., com a finalidade de obter a condição saturado com superfície seca. E para a produção dos concretos com agregados secos, optou-se por utilizar os agregados secos ao ar e verificar a umidade dos mesmos a cada mistura.

O autor verificou que conforme aumenta o teor de agregado graúdo reciclado, a resistência do concreto tende a diminuir e explica que, pelo fato de os agregados reciclados terem sido adquiridos a partir de um concreto de baixa resistência (aproximadamente 16,8 $\mathrm{MPa}$ ), acarretou também uma diminuição da resistência do concreto produzido com esses. Porém, essas reduções não aconteceram de forma linear. O pesquisador observou que para teores de substituição de $25 \%$, há uma tendência de diminuição de resistência de $15 \%$ a $20 \%$ do concreto.

A Figura 1 mostra a análise realizada pelo autor, da evolução da resistência à compressão de acordo com o teor de substituição de agregado graúdo natural por reciclado.

Figura 1: Resistência à compressão do concreto em função da idade para diferentes percentuais de substituição do agregado

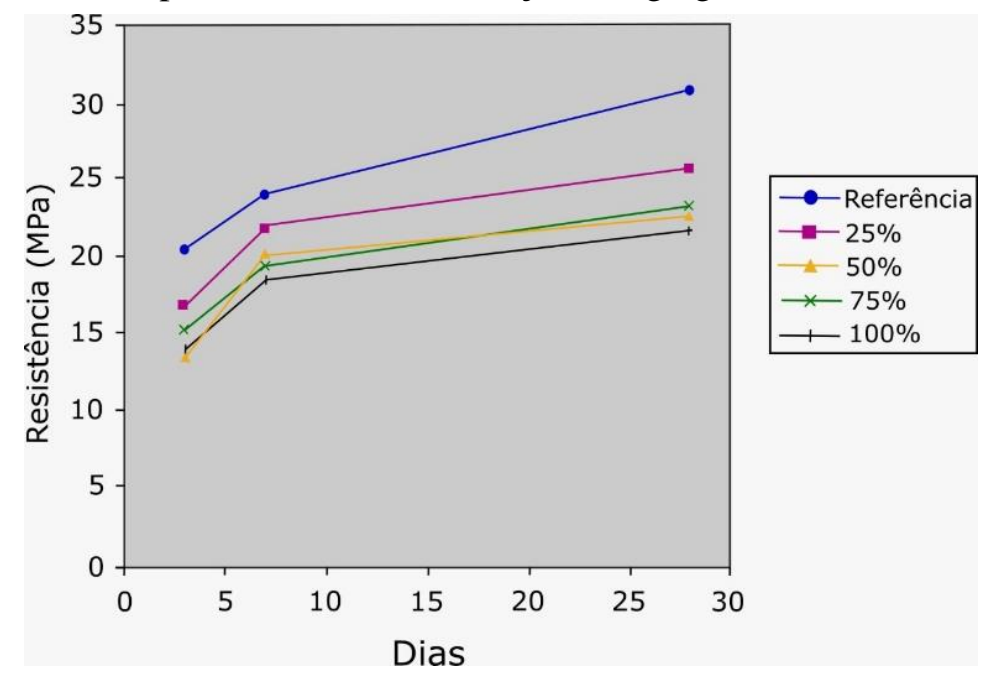

Fonte: Adpatado de Bazuco (1999).

Com base no estudo elaborado pelo autor, não houve diferenças significativas de resistência entre os concretos fabricados com agregados saturados e os concretos produzidos com agregados secos, os dois seguiram os mesmos aspectos de comportamento em relação aos traços realizados e aos teores de substituição.

No que tange a verificação da perda de abatimento, o autor optou por realizar o ensaio para os concretos referência e para os concretos com agregados reciclados secos, haja vista 
que os agregados reciclados possuem maior teor de absorção de água e por este motivo poderiam ocasionar maior perda de trabalhabilidade na mistura.

Os resultados do estudo apontam que quanto maior a incorporação de agregados reciclados na mistura, maior a perda de abatimento, da ordem de $15 \%$ a $30 \%$ após uma hora de mistura, e em relação aos concretos referências as perdas foram em média $15 \%$ a $25 \%$ maiores. Além das características do agregado reciclado, o autor ressalta que dentre outros fatores que também contribuem para perda de abatimento, uma possível explicação para os resultados é a diferença nos valores de umidade do ar. Os menores resultados de abatimento foram obtidos nos ensaios realizados quando os níveis de umidade do ar estavam mais baixos, o que pode ter causado maior perda de umidade para o ambiente.

\subsection{Borda; Cassol; Bueno (2016)}

Borda, Cassol e Bueno (2016) realizaram um estudo de análise da produção de concreto com agregado graúdo reciclado de concreto (AGRC), substituindo total e parcialmente o agregado graúdo natural. Nesse estudo foram elaborados três traços: com $100 \%$ de agregado natural (100\% AGN - Padrão), com 50\% de substituição de agregado natural por agregado reciclado (50\% AGRC) e com 100\% de substituição de agregado natural por agregado reciclado (100\% AGRC), sendo que nos traços contendo AGRC foi incorporado à mistura o aditivo plastificante redutor de água.

Os autores obtiveram como resultado que o traço contendo 100\% de AGRC expressou maior nível de resistência à compressão em relação ao confeccionado com agregado natural. Já o concreto contendo 50\% de AGRC teve resistência à compressão semelhante ao concreto convencional.

A Figura 2 mostra o resultado obtido pelos autores, da evolução da resistência à compressão de acordo com a quantidade de substituição do agregado graúdo natural pelo reciclado. 
Figura 2: Resistência à compressão do concreto em função da idade para diferentes percentuais de substituição do AGRC

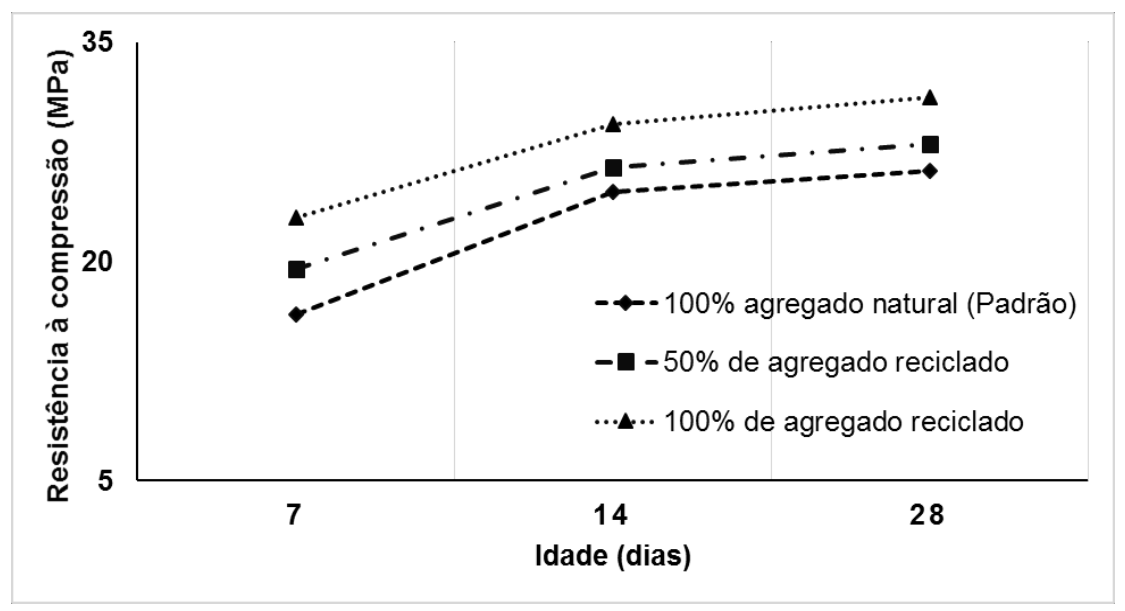

Fonte: Boda, Cassol e Bueno (2016).

Segundo Borda, Cassol e Bueno (2016), uma justificativa para o aumento da resistência à compressão dos concretos contendo AGRC é o efeito da hidratação avançada dos compostos cimentícios existente no AGRC. Os autores concluíram que o concreto produzido com agregados graúdos reciclados possui características parecidas, e até superiores, ao concreto convencional e que pode ser utilizado sem perdas nas propriedades estruturais, reduzindo o consumo de recursos naturais e contribuindo para o meio ambiente.

\subsection{Leite (2001)}

O estudo realizado por Leite (2001) teve como objetivo principal verificar a viabilidade de utilização de RCD na substituição total ou parcial ao agregado natural. Para isso, realizou cinco traços de concreto referência com relações água cimento variando de 0,40 a 0,80 e mais quinze traços com substituição em massa dos agregados miúdos e graúdos naturais por agregados de RCD, em diferentes porcentagens. Além disso, para a confecção dos traços com RCD foi realizado o procedimento de compensação da absorção de água do material e na maioria dos traços utilizou-se o aditivo superplastificante.

Desta forma, Leite (2001), traz uma série de avaliações sobre a influência da substituição do agregado natural pelo RCD e avalia, isolada e conjuntamente, a utilização de agregado miúdo reciclado (AMR) e agregado graúdo reciclado (AGR). A seguir, são citadas algumas constatações e conclusões da autora sobre o abatimento e a resistência do concreto.

Os valores de abatimento do concreto obtidos no estudo mostram que quanto maior o percentual de AGR no concreto, menor é o valor do abatimento. Segundo a autora, estes 
resultados estão em conformidade com as expectativas, devido à própria natureza do agregado reciclado que possui superfície mais rugosa e irregular, quando comparado ao natural. Com relação à resistência a compressão, o estudo apontou que o aumento de agregado graúdo reciclado provocou diminuição da resistência, como pode ser visto Figura 3.

Figura 3: Resistência à compressão do concreto em função de percentuais de Substituição de AMR e AGR

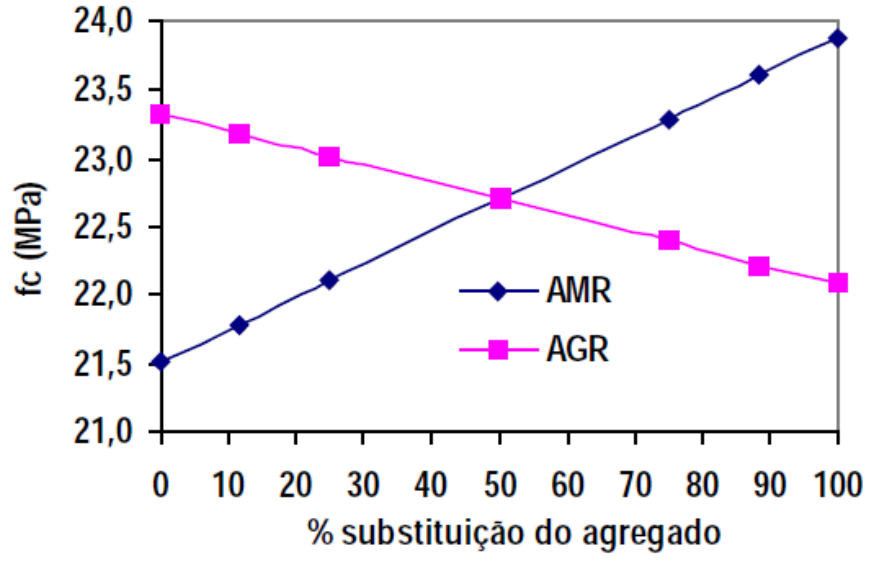

Fonte: Leite (2001).

Por meio da análise da Figura 3, pode-se avaliar também que maiores substituições de AMR melhoraram a resistência a compressão. Ao analisar a influência isolada do AMR na mistura, Leite (2001) identificou que o agregado miúdo aumenta a rigidez da matriz do concreto pois promove melhor aderência entre a pasta e o agregado, preenche os vazios e reduz a relação a/c da mistura do concreto.

Para a autora, as principais causas de diminuição da resistência em razão do AGR podem ser atribuídas à porosidade do agregado e à sua menor resistência, além de fatores relacionados a sua forma e textura. $\mathrm{O}$ agregado reciclado por ser mais rugoso e possuir maior capacidade de absorção, pode ter maior aderência com a matriz do concreto, uma vez nos poros do agregado podem ocorrer a precipitação dos cristais de hidratação e a absorção da pasta. Esta característica dos agregados reciclados, segundo a autora, pode proporcionar a melhoria da zona de transição entre pasta e agregado, entretanto, o agregado graúdo por ser maior e mais frágil, torna-se o ponto fraco do conjunto onde há mais chance de ocorrer a falha. 


\subsection{Vieira \& Molin (2004)}

Vieira \& Molin (2004) desenvolveram uma pesquisa utilizando agregado graúdo reciclado (AGR) e agregado miúdo reciclado (AMR) em substituição dos agregados naturais do concreto. Os agregados reciclados utilizados pelos autores foram provenientes de uma obra de demolição, sendo compostos de um elevado percentual de material cerâmico (cerca de $48 \%)$.

Para a análise do comportamento do concreto foi adotado um traço de referência sem a substituição dos agregados naturais para efeito de comparação e foram utilizados três percentuais de substituição: 0\%, 50\% e 100\% de substituição do AGR e do AMR. E para a fabricação do concreto definiram três relações de água/cimento (a/c): 0,40, 0,60 e 0,80. Para evitar a perda de trabalhabilidade da mistura, ocasionada pela alta taxa de absorção de água dos agregados reciclados, os autores utilizaram a compensação de água de 50\% da taxa de absorção dos agregados.

Vieira \& Molin (2004) analisaram a resistência à compressão aos 28 dias para diferentes teores de substituição dos agregados naturais pelos reciclados e para diferentes relações de a/c, a Figura 4 mostra os resultados obtidos.

Figura 4: Resistência à compressão em função da relação a/c para os diferentes percentuais de substituição do AMR e do AGR aos 28 dias

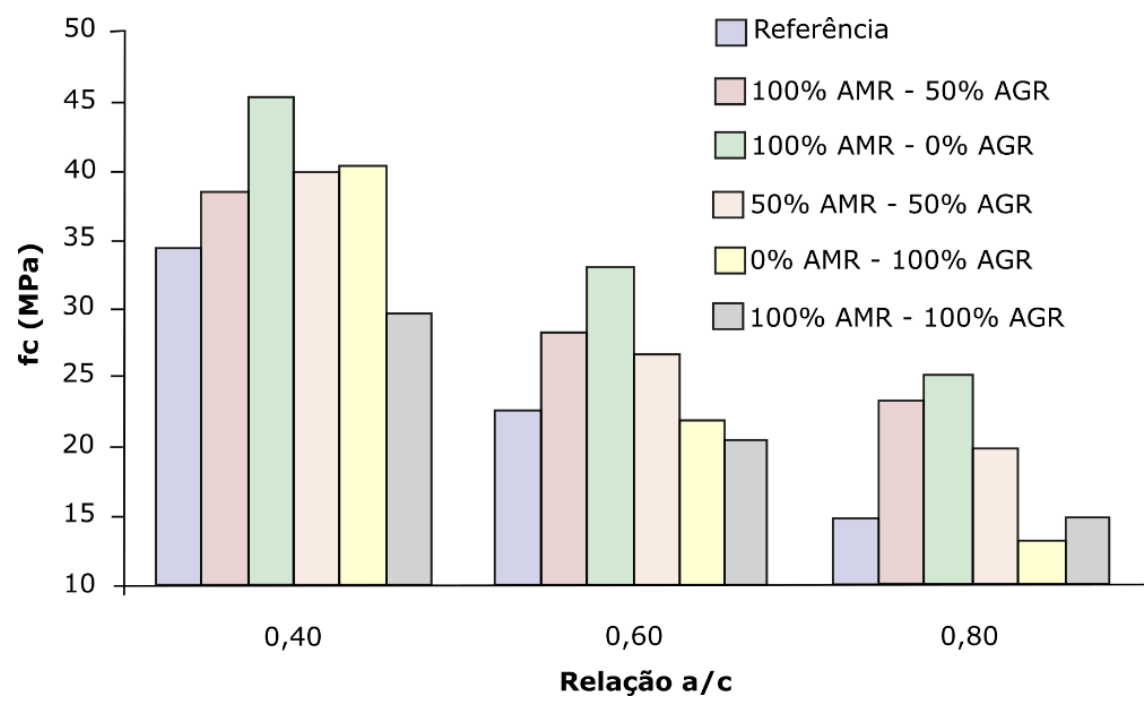

Fonte: Adaptado de Vieira \& Molin (2004).

Por meio da Figura 4Erro! Fonte de referência não encontrada. é possível perceber que em alguns casos houve aumento da resistência e em outros houve diminuição da 
resistência. Em relação aos traços com fator a/c=0,4 e a/c= 0,6 observou-se a redução da resistência apenas para o traço com 100\% de substituição dos agregados graúdos e miúdos, sendo essa redução de $16 \%$ e $11 \%$, respectivamente.

O melhor comportamento do desempenho em conjunto de agregados miúdos e graúdos reciclados foi apresentado nos concretos com 100\% de substituição de AMR e 50\% de AGR, e com 50\% de ambos, pois não houve perda de resistência em relação ao traço referência. O ganho foi notado para todas as classes de resistência, sendo o maior valor atingido pelo traço $100 \%$ AMR e 50\% AGR e relação a/c $=0,80$, que obteve um aumento de 56\% da resistência em relação ao concreto de referência (VIEIRA \& MOLIN, 2004).

De acordo com os autores, a substituição de 50\% de agregado graúdo reciclado e 50\% de agregado miúdo reciclado não afeta a resistência à compressão, muito menos a durabilidade do concreto. Entretanto, os traços com 100\% de substituição de RCD graúdo ou com a utilização de $100 \%$ de RCD graúdo e miúdo podem resultar em concretos com menor resistência ao ataque de agentes agressivos.

\subsection{Pelissari (2016)}

Pelissari (2016) realizou um estudo com o objetivo de produzir um concreto com resistência à compressão de $30 \mathrm{MPa}$, com substituição do agregado graúdo natural por agregado graúdo reciclado de concreto (ARC), sendo procedente da britagem de resíduos de concreto no estado endurecido.

Na primeira fase do estudo, Pelissari (2016) avaliou alguns procedimentos para diminuir a absorção da água de amassamento pelo agregado reciclado, que influencia no abatimento do concreto, destacando-se: a pré-saturação do agregado com a própria água de amassamento por 10 minutos antes de acrescentar os demais insumos do concreto, a utilização de aditivo e a adição de água extra para atingir o abatimento calculado. Na Figura 5 são apresentados os resultados do abatimento para a primeira fase do estudo. 
Figura 5: $1^{a}$ Fase - Resultados de abatimento pelo tronco de cone e massa específica

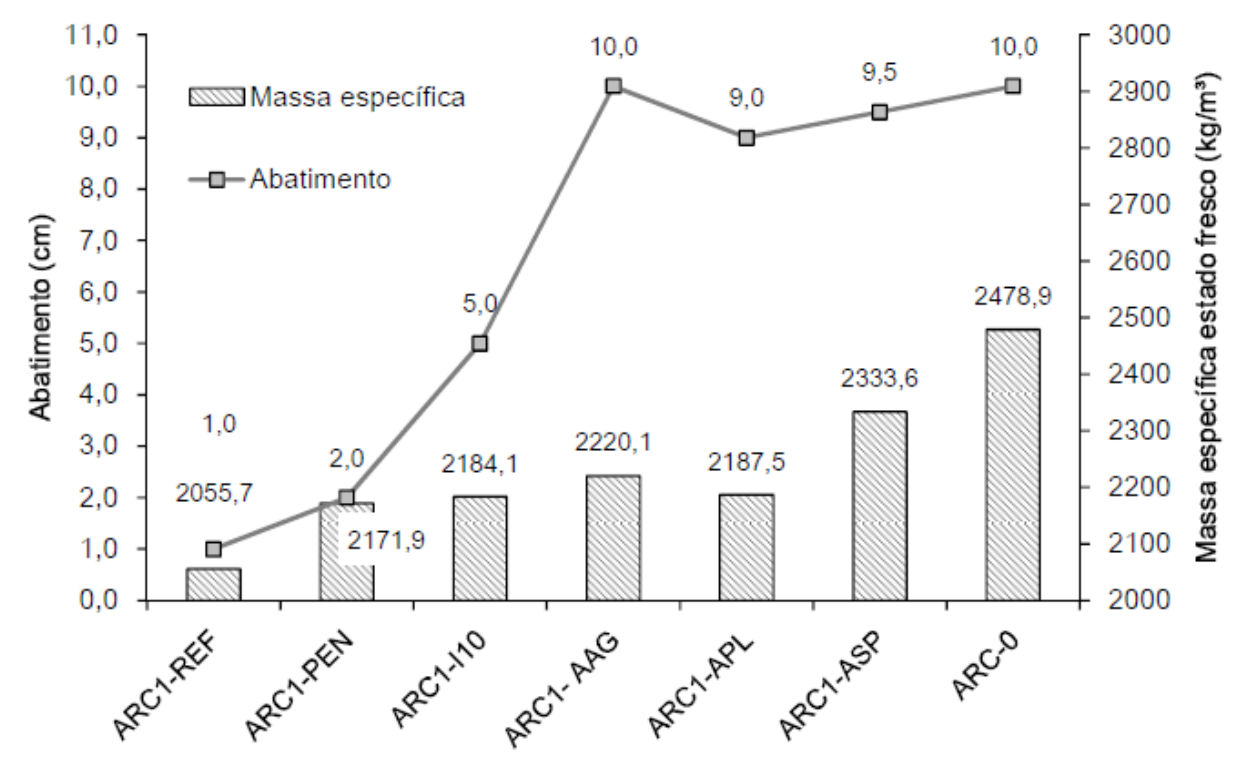

ARC-0: Concreto sem incorporaçāo de ARC, produzido com $100 \%$ de agregados naturais.

ARC1-RFF: sem nenhum procedimento para reduzir efeito da absorçāo

ARC1- AAG: adição de água suplementar

ARC1-APL: utilizaçāo de aditivo plastificante

ARC1-ASP: utilizaçāo de aditivo superplastificante

ARC1-I10: imersāo prévia do $\mathrm{ARC}$ por 10 minutos

ARC1-PEN: peneiramento prévio do ARC

Fonte: Pelissari (2016).

Pela análise da Figura 5, percebe-se que com relação ao abatimento do tronco de cone, o método que obteve melhor resultado foi o da utilização de água suplementar (ARC1AAG) com 10,0 cm de abatimento, seguido pela moldagem com uso de aditivo superplastificante (ARC1-ASP) e plastificante (ARC1-APL), respectivamente com 9,5 cm e 9,0 cm de abatimento e por último a moldagem com molhagem prévia com abatimento de $5,0 \mathrm{~cm}$. Além disso, para a primeira fase do estudo, também foram realizados ensaios de resistência à compressão, para os traços analisados. A Figura 6 apresenta o resumo dos resultados obtidos. 
Figura 6: $1^{\text {a }}$ Fase - Resultados dos testes de resistência à compressão

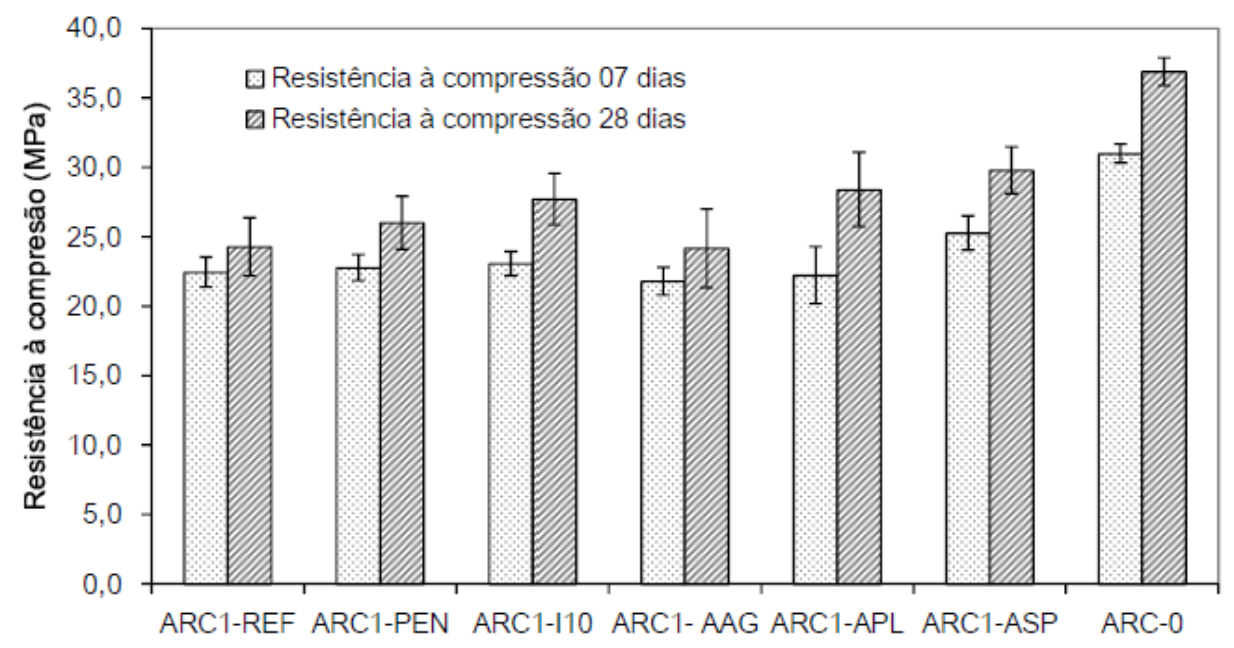

Fonte: Pelissari (2016).

No que tange a resistência à compressão da $1^{\text {a }}$ fase, a Figura 6 mostra que nenhum dos concretos fabricados com agregado reciclado atingiu a resistência à compressão de $30 \mathrm{MPa}$. Em contrapartida, pelo gráfico da Figura 7 que compara as variações de resistência, pode-se observar que houve melhoria dos resultados em relação ao ARC1-REF (concreto com RCD, sem nenhuma estratégia para reduzir o efeito da absorção de água) em todos os concretos, exceto no ARC1-AAG, que em razão do aumento da água de amassamento teve a relação água/cimento teórica de 0,54 aumentada para 0,64. Além disso, nota-se que os maiores ganhos de resistência foram obtidos nos concretos com aditivo.

Figura 7: $1^{\mathrm{a}}$ Fase - Percentuais de variação nos valores de resistência

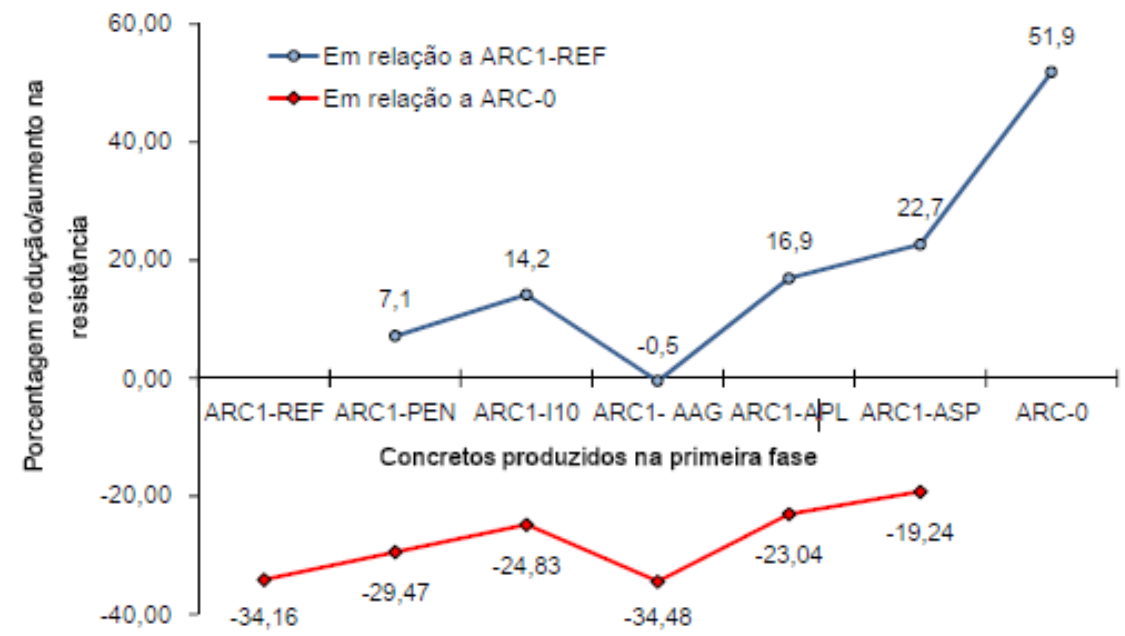

Fonte: Pelissari (2016).

Na segunda fase, Pelissari (2016) fez uma investigação do efeito de diferentes porcentagens de substituição do agregado graúdo natural pelo agregado reciclado, nas 
seguintes porcentagens: $10 \%, 20 \%, 50 \%$ e $100 \%$. A autora utilizou os resultados obtidos na primeira fase para determinar quais procedimentos seriam adotados na segunda fase. Dentre eles, cabe destacar que foi utilizado o aditivo superplastificante e a pré-saturação do agregado graúdo com a água de amassamento por 10 minutos. Para verificar a necessidade de uso do aditivo, foi feito o ensaio do tronco de cone. $\mathrm{O}$ aditivo foi usado nos concretos com porcentagem a partir de $20 \%$ de RCD, e em todas as moldagens a autora atingiu o abatimento pretendido de $10 \mathrm{~cm}$, sendo que o mínimo registrado foi $10,0 \mathrm{~cm}$. Na Figura 8 são apresentados os resultados de resistência à compressão para os ensaios da segunda fase.

Figura 8: $2^{\mathrm{a}}$ Fase - Resultados de resistência à compressão

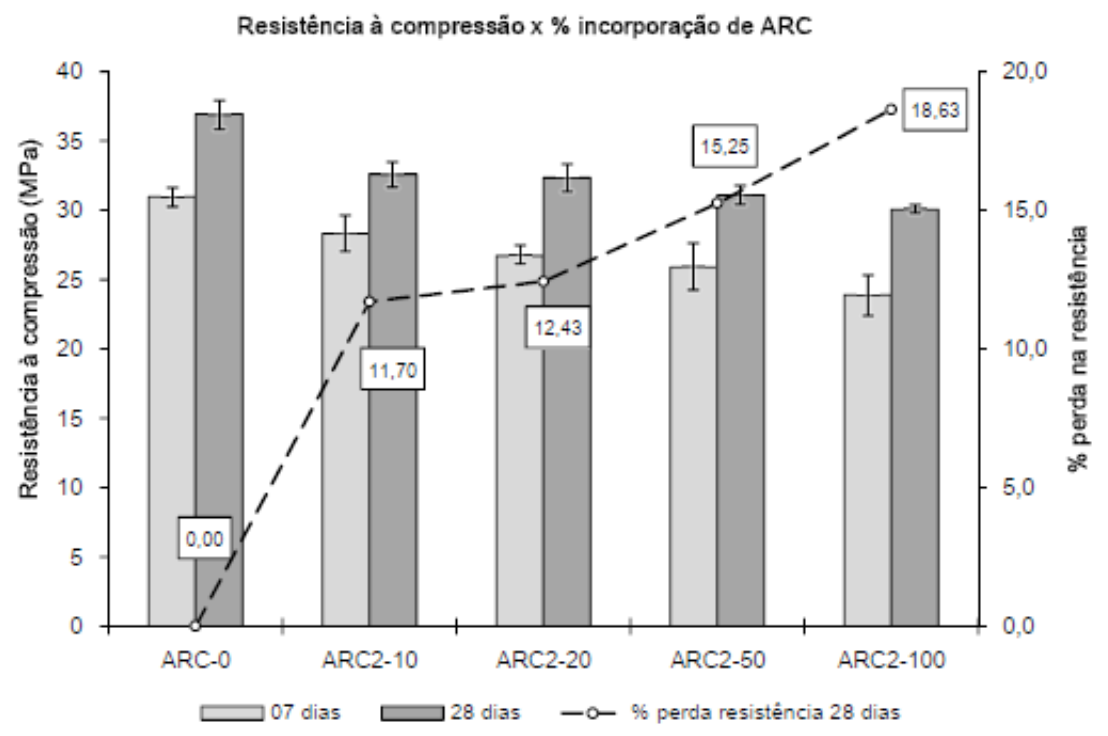

Fonte: Pelissari (2016).

A Figura 8 mostra que todos os concretos atingiram a resistência à compressão predefinida de $30 \mathrm{MPa}$ e que para maiores porcentagens de substituição de ARC, aumentou também a queda de resistência em relação ao traço de referência. Pelissari (2016) afirma que existe uma relação inversa entre a resistência de um material e sua porosidade, justificando assim que para os traços que possuem maior incorporação de ARC, existe um aumento do índice de vazios do concreto, comprometendo a resistência deste. Outro fator citado pela autora é que a perda de resistência também está relacionada à resistência e à relação a/c do concreto que deu origem ao ARC.

\subsection{Araújo et al. (2016)}


O estudo realizado por Araújo et al. (2016) utilizou como agregado reciclado resíduos de concreto e argamassa em substituição ao agregado natural graúdo. De acordo com os autores, com o intuito de obter melhor trabalhabilidade do concreto, o material foi peneirado e a porção passante pela peneira de $4,75 \mathrm{~mm}$ foi descartada. Para a realização do estudo, os autores definiram o traço referência (Traço -0) e a partir deste, calcularam mais quatro traços com substituição de $19 \%, 43 \%, 75 \%$ e $100 \%$ de brita 0 e brita 1 por RCD e mais um traço com $26 \%$ de substituição apenas de brita 1 .

Em todos os traços foi feito o uso de aditivo superplastificante com o objetivo de obter um abatimento de $100 \mathrm{~mm}$. Sendo que o ajuste da quantidade foi realizado com base na porcentagem de substituição de agregado reciclado na mistura chegando a $1,2 \%$ no traço com $100 \%$ de RCD. A partir dos resultados obtidos, pode-se observar que somente os traços com $75 \%$ (C-75) e 100\% (C-100) de RCD não tiveram resultado de abatimento do concreto dentro do intervalo determinado, sendo respectivamente $215 \mathrm{~mm}$ e $70 \mathrm{~mm}$. Os autores não identificaram uma razão para o resultado do traço C-75.

Tabela 1: Resistência à compressão do concreto

\begin{tabular}{lccl}
\hline & Substituição $(\boldsymbol{\%})$ & $\mathbf{f}_{\mathbf{c m}, \mathbf{j}=\mathbf{7}}(\mathbf{M P a})$ & $\mathbf{f}_{\mathbf{c m}, \mathbf{j}=\mathbf{2 8}}(\mathbf{M P a})$ \\
\hline C-0 & 0 & $26,95 \pm 4,02$ & $36,39 \pm 1,56$ \\
C-19 & 19 & $33,97 \pm 1,39$ & $41,23 \pm 0,59$ \\
C-43 & 43 & $32,79 \pm 3,55$ & $39,60 \pm 1,98$ \\
C-75 & 75 & $29,34 \pm 1,52$ & $35,79 \pm 0,48$ \\
C-100 & 100 & $28,77 \pm 1,38$ & $38,30 \pm 1,07$ \\
CT-26 & 26 & $32,75 \pm 1,70$ & $37,82 \pm 1,39$ \\
\hline
\end{tabular}

Fonte: Adaptado de Araújo et al. (2016).

A Tabela 1 mostra os resultados de resistência à compressão dos concretos produzidos. Os valores de resistência aos 7 dias, apontam que houve ganho de $75 \%$ da resistência aos 28 dias no traço C-100 e cerca de $83 \%$ no restante dos traços. Os autores concluíram que esses resultados podem ser atribuídos a absorção de água pelos agregados graúdos, que é liberada mais tarde favorecendo a hidratação do cimento. Aos 28 dias a menor resistência à compressão foi obtida no traço com $75 \%$ de RCD e foi também o único que obteve resultado menor que o traço referência C-0; já maior resistência foi obtida no traço com 19\% de RCD.

Para verificar se a porcentagem de substituição do agregado natural por RCD influenciou nos resultados das propriedades mecânicas do concreto, Araújo et al. (2016) 
realizaram o teste de comparações múltiplas de médias. Os resultados apontam que é admissível a utilização de $100 \%$ de agregado reciclado para produção de concreto estrutural e que os valores de resistência são próximos aos do concreto de referência, considerando o traço do estudo realizado. Entretanto os autores apontam que estas conclusões divergem dos estudos anteriores, que relatam diminuição de resistência, e afirmam que o principal motivo para esse contraste é devido às características do agregado reciclado, uma vez que Araújo et al. (2016) utilizaram um RCD com escassa quantidade de material cerâmico e com valores de massa específica maior do que os estudos comparados.

No que diz respeito ao traço CT-26 (com 26\% de RCD), Araújo et al. (2016) realizaram tratamento do agregado reciclado para obter grãos com características melhores. O RCD foi separado mecanicamente no equipamento de abrasão "Los Angeles" onde se obteve uma taxa de recuperação de 53\%. Desta forma, os autores obtiveram um agregado reciclado com maior massa específica e menor absorção, quando comparados com o agregado não tratado, sendo estas as razões apontadas pelos autores para o menor consumo de aditivo em relação aos outros traços.

\section{DISCUSSÃO DOS RESULTADOS}

Por meio dos estudos analisados, percebe-se que as propriedades do concreto mais afetadas pela substituição do agregado natural pelo agregado de RCD são a trabalhabilidade e a resistência à compressão.

Em relação ao ensaio de abatimento de tronco de cone, é possível observar que em todos os estudos citados nesta pesquisa, o concreto contendo agregado proveniente de RCD tende a apresentar um menor abatimento quando comparado com o concreto produzido com agregados naturais. Observando os dados analisados, pode-se dizer que tal fato ocorre em razão da maior porosidade do agregado de RCD, como pode-se observar nos estudos de Bazuco (1999), Leite (2001), Pelissari (2016) e Araújo et al. (2016). Além disso, pode-se afirmar que quanto maior a porcentagem de substituição do agregado natural pelo agregado de RCD, maior é a perda de trabalhabilidade da mistura, como visto nos estudos de Bazuco (1999) e Leite (2001).

Diante disso, para melhorar o abatimento do concreto contendo RCD existem algumas medidas adotadas na fabricação desses, como visto nos trabalhos citados, pode-se adotar a pré-saturação dos agregados de RCD - conforme utilizado por Bazuco (1999) e Pelissari 
(2016), a compensação de água - adotada por Vieira \& Molin (2004), Leite (2001) e Pelissari (2016) e/ou adicionar aditivos às misturas - conforme trabalhos de Leite (2001), Borda, Cassol e Bueno (2016), Pelissari (2016) e Araújo et al. (2016). A escolha de qual procedimento a ser adotado depende das condições do agregado reciclado, do desempenho que se pretende alcançar com os concretos contendo RCD, e do ponto de vista econômico, visto que a incorporação de aditivos pode aumentar o custo final do concreto.

Em contrapartida, existem dificuldades de se realizar a pré-saturação dos agregados no canteiro de obras, visto que seria necessário um maior controle no processo de fabricação para garantir a adequada pré-saturação do agregado de RCD. Ademais, para atingir um grau de saturação específico do RCD, é necessário que haja um profissional habilitado para tal função e equipamentos adequados, o que aumenta o grau de complexidade deste procedimento.

No que tange ao procedimento de compensação de água, o aumento da quantidade de água na mistura pode promover o aumento da relação a/c e reduzir a resistência do concreto. Como pode ser visto no estudo de Pelissari (2016), o traço que utilizou água suplementar obteve uma queda de resistência em relação ao traço sem nenhuma estratégia para reduzir o efeito da absorção de água.

A não adição de água na mistura também altera a relação a/c disponível para a cristalização do cimento, uma vez que o agregado de RCD é maios poroso, ele acaba absorvendo maior quantidade de água, quando se compara com o agregado natural. Tal afirmação pode ser considerada com os resultados de porosidade obtidos por de Bazuco (1999), Leite (2001), Pelissari (2016) e Araújo et al. (2016) e pela perda de trabalhabilidade nos traços com agregado de RCD, obtidas por Bazuco (1999) e Leite (2001).

Diante dos resultados analisados, pode-se dizer que a incorporação de aditivo superplastificante na mistura é a melhor estratégia para melhorar o abatimento do traço com RCD. Pois observando os resultados da primeira fase do estudo de Pelissari (2016), pode-se perceber que o traço de RCD com adição de aditivo superplastificante obteve um ganho de resistência, quando comparado com o traço de RCD sem nenhuma medida para melhorar o abatimento. Sendo que o traço de RCD com aditivo superplastificante foi o que obteve menor perda de resistência, quando comparado ao traço referência, com agregado natural.

Considerando que a incorporação de aditivo pode aumentar o custo do concreto, é possível adotar uma estratégia para reduzir o consumo desses, conforme visto no trabalho 
de Araújo et al. (2016) para que seja possível reduzir o consumo de aditivo nos traços contendo agregado de RCD é necessário realizar o tratamento do agregado, para que haja maior massa especifica e menor absorção de água.

Em relação aos resultados de resistência à compressão dos estudos analisados, observa-se que houve variação no comportamento dos concretos, ora apresentando aumento da resistência com a incorporação de agregado de RCD e outrora a redução da resistência.

O Quadro 1 fornece um resumo dos resultados encontrados por cada autor.

Quadro 1: Resultados de resistência à compressão obtidos aos 28 dias

\begin{tabular}{|c|c|c|}
\hline Autores & $\begin{array}{c}\text { Tipo de RCD e \% de } \\
\text { substituição }\end{array}$ & Resultados \\
\hline Bazuco (1999) & $\begin{array}{l}\text { Agregado graúdo reciclado de } \\
\text { concreto. } \\
\text { Substituição: } 0 \%, 25 \%, 50 \%, \\
75 \% \text { e } 100 \% \text {. }\end{array}$ & $\begin{array}{l}\text { Redução da resistência a compressão } \\
\text { conforme aumenta-se o teor de agregados } \\
\text { graúdos reciclados, sendo que a utilização } \\
\text { dos agregados no estado seco ou saturado não } \\
\text { ocasionou em diferenças significativas nos } \\
\text { resultados de resistência. }\end{array}$ \\
\hline $\begin{array}{l}\text { Borda, Cassol e } \\
\text { Bueno (2016) }\end{array}$ & $\begin{array}{l}\text { Agregado graúdo de concreto } \\
\text { (AGRC) } \\
\text { Substituição: } 50 \% \text { e } 100 \% \text {. }\end{array}$ & $\begin{array}{l}\text { Aumento de resistência no traço contendo } \\
100 \% \text { de agregado graúdo reciclado em } \\
\text { relação ao concreto com agregado natural. }\end{array}$ \\
\hline Leite (2001) & $\begin{array}{l}\text { Agregado graúdo misto com } \\
\text { 26,33\% de material cerâmico. } \\
\text { Substituição: } 0 \%, 11,5 \%, 50 \%, \\
88 \% \text { e } 100 \% \text {. }\end{array}$ & $\begin{array}{l}\text { Redução da resistência com o aumento do } \\
\text { agregado graúdo reciclado e aumento da } \\
\text { resistência com maiores substituições do } \\
\text { agregado miúdo natural pelo agregado miúdo } \\
\text { de RCD. }\end{array}$ \\
\hline $\begin{array}{c}\text { Viera \& } \\
\text { Molin (2004) }\end{array}$ & $\begin{array}{l}\text { Agregado graúdo reciclado } \\
\text { (AGR) com } 48 \% \text { de material } \\
\text { cerâmico. } \\
\text { Substituição: } 0 \%, 50 \% \text { e } 100 \% \text {. }\end{array}$ & $\begin{array}{l}\text { Houve perda de resistência em alguns traços, } \\
\text { entretanto a maioria dos traços obtiveram } \\
\text { resistência maior ou próxima à do concreto } \\
\text { referência. }\end{array}$ \\
\hline Pelissari (2016) & $\begin{array}{l}\text { Agregado graúdo reciclado de } \\
\text { concreto (ARC). } \\
\text { Substituição: } 10 \%, 20 \%, 50 \% \text { e } \\
100 \% \text {. }\end{array}$ & $\begin{array}{l}\text { Na } 2^{a} \text { fase do estudo, todos os traços com } \\
\text { substituição do agregado graúdo natural pelo } \\
\text { agregado reciclado de RCD alcançaram a } \\
\text { resistência predefinida, sendo que para as } \\
\text { maiores porcentagens de substituição de } \\
\text { RCD, houve redução da resistência em } \\
\text { relação ao traço referência. }\end{array}$ \\
\hline $\begin{array}{l}\text { Araújo et al. } \\
\quad(2016)\end{array}$ & $\begin{array}{l}\text { Agregado graúdo reciclado de } \\
\text { concreto e argamassa. } \\
\text { Substituição: } 0 \%, 19 \%, 26 \%, \\
43 \%, 75 \% \text { e } 100 \% \text {. }\end{array}$ & $\begin{array}{l}\text { Todos os traços, com exceção do traço com } \\
75 \% \text { de RCD graúdo, obteve resistência } \\
\text { maior que a do concreto referência. }\end{array}$ \\
\hline
\end{tabular}

Fonte: Autoria própria (2020).

Analisando os dados do Quadro 1, observa-se a redução da resistência nos concretos contendo agregados de RCD nos estudos de Bazuco (1999), Leite (2001) e Viera \& Molin (2004). Os motivos para essa redução são semelhantes, sendo justificados pela composição 
dos agregados de RCD, que possuem baixa resistência, alta porosidade, textura mais rugosa, e elevada composição de materiais cerâmicos, contribuindo assim para a redução da resistência dos concretos fabricados com esses agregados.

Outro ponto relevante é que nos estudos de Bazuco (1999), Leite (2001) e Viera \& Molin (2004), observou-se que quanto maior a incorporação de agregado graúdo de RCD, maior foi a perda de resistência dos concretos. Em contrapartida nos estudos de Leite (2001) e de Viera \& Molin (2004), nos traços contendo maiores teores de substituição do agregado miúdo natural pelo de $\mathrm{RCD}$, a resistência à compressão dos concretos aumentaram.

Analisando os resultados dos trabalhos de Borda, Cassol e Bueno (2016) e Araújo et al. (2016), pode-se observar uma divergência em relação aos estudos citados anteriormente. Uma vez que a incorporação de agregado graúdo reciclado de RCD promoveu o aumento da resistência à compressão. O motivo para esse comportamento está relacionado às características do agregado de RCD, sendo que estes autores utilizaram agregado proveniente de resíduos de concreto, possuindo escassa quantidade de material cerâmico, menor porosidade e maior resistência, quando comparado aos agregados graúdos de RCD das demais pesquisas.

Pelissari (2016) também se utilizou do ARC em substituição do agregado graúdo natural, sendo que analisando seus resultados pode-se perceber que para todos os traços com substituição do agregado natural por agregado de $\mathrm{RCD}$, foi possível atingir a resistência de projeto. Entretanto, ao comparar os traços produzidos com ARC com o traço referência, observa-se que todos alcançaram resistência à compressão menor que a do traço referência. Tal fato pode ser justificado pela maior porosidade e menor resistência do concreto que deu origem ao ARC utilizado nesta pesquisa, quando se compara aos trabalhos de Borda, Cassol e Bueno (2016) e Araújo et al. (2016).

\section{CONCLUSÃO}

Observa-se por meio dos estudos analisados que os concretos fabricados com agregados de RCD possuem comportamentos distintos em razão da variedade da composição desse material, o que justifica a necessidade de aprimorar os estudos existentes sobre a utilização do RCD como agregado no concreto. 
Sendo assim, recomenda-se que as pesquisas voltadas para essa área realizem um estudo do tipo de RCD a ser incorporado no concreto, e adotem medidas que possam melhorar o desempenho desses traços.

Em relação ao abatimento, é necessário realizar um estudo prévio para analisar a condição do agregado reciclado e definir o procedimento mais adequado para melhorar o abatimento, de forma que não ocasione a alta redução da resistência final do concreto.

Conclui-se que é possível fabricar concretos com agregados reciclados com valores de resistência semelhante ou até mesmo superiores ao do concreto convencional, e que isso está diretamente ligado à qualidade do agregado proveniente de RCD.

Além disso, a substituição dos agregados naturais pelos agregados de RCD podem promover a atenuação dos impactos ambientais por meio da redução do consumo de recursos naturais e da diminuição do volume de resíduos de construção e demolição, além de evitar o descarte inadequado dos RCD.

\section{REFERÊNCIAS}

ANGULO, S. C. Variabilidade de agregados graúdos de resíduos de construção e demolição reciclados. Escola Politécnica da Universidade de São Paulo. São Paulo, p. 172. 2000 .

ANGULO, S. C.; FIGUEIREDO, A. D. D. Concreto com agregados reciclados. In: ISAIA, G. C. Concreto: Ciência e Tecnologia. São Paulo: Ibracon, 2011. Cap. 47

ARAÚJO, D. de L. et al. Influência de agregados reciclados de resíduos de construção nas propriedades mecânicas do concreto. Revista Eletrônica de Engenharia Civil, v.11, n. 1, p. 16-34, 2016.

ASSOCIAÇÃO BRASILEIRA DE LIMPEZA PÚBLICA E RESÍDUOS ESPECIAIS ABRELPE. Panorama dos Resíduos Sólidos no Brasil 2015. São Paulo, 2015.

ASSOCIAÇÃO BRASILEIRA DE LIMPEZA PÚBLICA E RESÍDUOS ESPECIAIS ABRELPE. Panorama dos Resíduos Sólidos no Brasil 2016. São Paulo, 2016.

ASSOCIAÇÃO BRASILEIRA DE LIMPEZA PÚBLICA E RESÍDUOS ESPECIAIS ABRELPE. Panorama dos Resíduos Sólidos no Brasil 2018/2019. São Paulo, 2019.

ASSOCIAÇÃO BRASILEIRA DE NORMAS TÉCNICAS - ABNT. NBR 7211: Agregados para concreto - Especificação. Rio de Janeiro, 2005. 
ASSOCIAÇÃO BRASILEIRA DE NORMAS TÉCNICAS - ABNT. NBR 15116: Agregados reciclados de resíduos sólidos da construção civil - Utilização em pavimentação e preparo de concreto sem função estrutural - Requisitos. Rio de Janeiro, 2004.

ASSOCIAÇÃO BRASILEIRA PARA RECICLAGEM DE RESÍDUOS DA CONSTRUÇÃO CIVIL E DEMOLIÇÃO - ABRECON. O que é entulho? Disponível em: https://abrecon.org.br/entulho/o-que-e-entulho/. Acesso em: 30 mar. 2020.

ASSOCIAÇÃO NACIONAL DAS ENTIDADES DE PRODUTORES DE AGREGADOS PARA CONSTRUÇÃO - ANEPAC. O Mercado de Agregados no Brasil. São Paulo, p. 11. 2015.

BAUER, L. A. F. Materiais de Construção. 5.ed. Rio de Janeiro: LTC, v. I, 2008.

BAZUCO, R. S. Utilização de agregados reciclados de concreto para produção de novos concretos. Universidade Federal de Santa Catarina. Florianópolis, p. 128. 1999.

BORDA, W. F. D.; CASSOL, G.; BUENO, L. D. S. Confecção de concreto com utilização de agregado reciclado. Anais do Congresso Técnico Científico da Engenharia e da Agronomia, Foz do Iguaçu, Setembro 2016.

BRASIL. RESOLUÇÃO CONAMA n 307, de 5 de julho de 2002. Ministério do Meio Ambiente. Brasil. 2002.

FEDERACION INTERAMERICANA DEL CEMENTO (FICEM). Informe Estadístico 2018. Bogotá, Colombia. 2018

LAURIANO, L. A. Como anda a gestão da sustentabilidade no setor da construção? Fundação Dom Cabral. Nova Lima, p. 49. 2013.

LEITE, M. B. Avaliação das propriedades mecânicas de concretos produzidos com agregados reciclados de resíduos de construção e demolição. Universidade Federal do Rio Grande do Sul. Porto Alegre, p. 290. 2001.

NETO, J. da C. M. et al. Impactos causados pelos resíduos de construção e demolição no meio ambiente urbano. Anais do Congresso Brasileiro de Ciência e Tecnologia em Resíduos e Desenvolvimento Sustentável, Florianópolis, 2004.

NEVILLE, A.M. Propriedades do Concreto. 5.ed. Porto Alegre: Bookman Editora Ltda, 2016.

NEVILLE, A. M.; BROOKS, J. J. Tecnologia do Concreto. 2.ed. Porto Alegre: Bookman Editora Ltda, 2013.

ORTEGA, S. G. Sustentabilidade na construção civil: significados, práticas e ideologia. Organizações e Sustentabilidade, Londrina, v. 2, p. 112-137, junho 2014.

PEDROSO, F. L. Concreto: as origens e a evolução do material construtivo mais usado pelo homem. Concreto e Construções, São Paulo, p. 14-19, 2009. 
PELISSARI, V. Propriedades de concretos produzidos através da utilização de agregados reciclados de concreto. Dissertação de Mestrado. Universidade Tecnológica Federal do Paraná, Curitiba, p. 122. 2016.

VIEIRA, G. L.; MOLIN, D. C. C. D. Viabilidade técnica da utilização de concretos com agregados reciclados de resíduos de construção e demolição. Ambiente Construído, Porto Alegre, p. 47-63, 2004. 